\title{
Research Square \\ Comparison of Effectiveness Using Different Dual Broncho- dilator Agents in Chronic Obstructive Pulmonary Disease Treatment
}

Shih-Lung Cheng ( $\nabla$ shihlungcheng@gmail.com )

Department of Internal Medicine, Far Eastern Memorial Hospital

Research article

Keywords: Chronic obstructive pulmonary disease (COPD), dual bronchodilator, LABA/LAMA

Posted Date: February 25th, 2020

DOl: https://doi.org/10.21203/rs.2.24531/v1

License: (c) (1) This work is licensed under a Creative Commons Attribution 4.0 International License.

Read Full License 


\section{Abstract}

\section{Background}

The efficacy and safety of fixed dual long-acting bronchodilators for chronic obstruction pulmonary disease (COPD) patients has been well established; however, there is a paucity of clinical effectiveness comparison in patients with COPD treatment. The aim of the current study was to compare the efficacy of three once daily dual bronchodilator agents in patients with COPD.

\section{Methods}

Patients with diagnosed COPD and treated with a long-acting beta agonist (LABA) + long-acting muscarinic antagonist (LAMA) fixed-dose combination therapy (UME/VIL [umeclidinium and vilanterol inhalation powder], IND/GLY [indacaterol and glycopyrronium], and TIO/OLO [tiotoprium and olodaterol]) were enrolled in this retrospective study over a period of 12 months. Effectiveness assessments were evaluated using a COPD assessment test (CAT) and lung function parameters. Besides, times for acute exacerbation were also assessed.

\section{Results}

The enrolled patients' number was 77 in IND/GLY, 76 in UME/VIL and 83 in TIO/OLO. Lung function measurements with FEV1 had significantly improved for patients using TIO/OLO (98.7 $\mathrm{ml})$ compared to those of IND/GLY (65.2 ml) and UMEC/VIL $(64.4 \mathrm{ml})(p<0.001)$. CAT scores were also significantly decreased in patients treated with TIO/OLO (CAT down 5.6) than those with IND/GLY (3.8) and UMEC/VIL (3.9) $(p=0.03)$. Acute exacerbation was also reduced in patients using TIO/OLO (4.8\%) compared with those using IND/GLY (10.4\%) and UMEC/VIL (10.5\%) $(p=0.01)$.

\section{Conclusion}

Significant improvement in pulmonary function, symptoms were demonstrated after 12 months of LABA+LAMA fixed-dose combination therapy with 3 different treatment options. TIO/OLO demonstrated higher therapeutic effects compared with UME/VIL or IND/GLY. Determining clinical relevance will require a well-designed randomized controlled trial.

Key Words: Chronic obstructive pulmonary disease (COPD), dual bronchodilator, LABA/LAMA

\section{Background}

Chronic Obstructive Pulmonary Disease (COPD) is a primary driver of morbidity and mortality globally with estimates placing it as a leading cause of death by 2020.[1,2] The Asia-Pacific region reports the highest burden of COPD in terms of mortality, years spent living with disability, and years of life lost.[3] In Asia, the prevalence of COPD is high (6.2\% in 2012), with a similar estimated prevalence in Taiwan (approximately $6.1 \%-9.5 \%$ ).[4,5] Mortality due to COPD has risen gradually over time in Taiwan. [6] 
Pharmacologic therapy aims to reduce symptoms of COPD, increase exercise capacity, and improve patient quality of life and prognosis. [7] Bronchodilator agents are the cornerstones for COPD treatment. Long-acting beta agonist (LABA) and long-acting muscarinic antagonist (LAMA) bronchodilator agent provides an effective treatment option in the management of COPD and is recommended as the first-line fixed-dose combination (FDC) treatment option in the majority of symptomatic patients with COPD, either alone or in combination. Among pharmacological therapy, dual bronchodilator agents with LABA and LAMA combination were the important therapy strategy in advanced COPD status, especial in the FLAME study. [8] Patients with more symptoms and previously frequent exacerbations (Group D) should treat with dual bronchodilator agents initially in 2017 revised GOLD guidelines. [9] Besides, other dual bronchodilator agents such as UME/VIL [umeclidinium and vilanterol] [10] and TIO/OLO [tiotoprium and olodaterol] [11] have also the efficacy for reducing exacerbation rates and improved lung function status. However, evidence efficacy of LABA/LAMA FDCs is limited owing to scarce head-to-head comparison data among the Taiwanese population. Of the medications used for this study, UME/VIL, IND/GLY (Indacaterol + Glycopyrronium), and TIL/OLO are all fixed dual long-acting bronchodilators from two classes (LABA, long acting $\beta 2$ agonists + LAMA, long acting muscarinic antagonists). The efficacy of these medications on COPD patients in Taiwan remains unknown and therefore we would compare the effectiveness in clinical real world practice.

\section{Material And Methods}

\section{Study objectives}

The study was a retrospective survey for the effectiveness among three dual bronchodilator agents. A total of 236 patients with diagnosed COPD and treated with UME/VIL (umeclidinium and vilanterol inhalation powder), IND/GLY (indacaterol and glycopyrronium), and TIO/OLO (tiotoprium and olodaterol) were included in the current study. All patients were from Far Eastern Memorial Hospital (FEMH) in Taiwan and were examined and treated over a period of 12 months. All patients were over 40 years of age, were current or former smokers (smoking pack/day-year $>10$ ), were symptomatic (eg, chronic airway symptoms and signs such as coughing, breathlessness, wheezing and chronic airway obstruction), and their pulmonary function was consistent with a diagnosis of COPD (FEV1/FVC $<70 \%$, post-bronchodilator FEV1< $80 \%$ predicted value, and GOLD II - GOLD IV). Patients were excluded from the current study for suspected or combined sleep apnea, presenting with a comorbid pulmonary disease or other uncontrolled systemic disease, abnormal chest $x$-ray results, evidence of alcohol abuse, or presenting with a lower respiratory tract infection treated with antibiotics and systemic steroids. Ethical approval from the hospital was approval and obtained. (IBR Number: 107006-E)

\section{Evaluation of Therapeutic Effects}

All medical records were reviewed and analyzed. Patients were examined for the frequency of acute episode of symptomatic COPD, including a COPD assessment test (CAT) and evaluation of lung function (forced expiratory volume in 1 second [FEV1] and forced vital capacity [FVC]). 
Lung function dependent variables were defined using the difference between baseline values and values obtained after 12 months of treatment. Differences in CAT scores were calculated by subtracting CAT at 12 months from baseline CAT. FEV1 and FVC differences were calculated by subtracting the FEV1 and FVC at 12 months from baseline FEV1 and FVC. Besides, times for acute exacerbation (AE) were also measured during the treatment period and compared the AE rates difference in these three drugs' patients.

\section{Statistical analysis}

Descriptive statistics for treatment medication, demographics, comorbidities and clinical outcomes are provided. Continuous variables are reported as mean and standard deviation (SD). Chi-square tests of independence and ANOVA F-tests were conducted for each variable and treatment medication. ANOVA multiple comparisons, using Tukey's HSD (honest significant difference) tests, were conducted between users of different medication for all clinical outcomes. All statistical analyses were performed using SAS ${ }^{\circledR}$ version 9.4 (Windows NT version, SAS Institute, Inc., Cary, NC, USA) and R (version 3.4.2; R Foundation for Statistical Computing, Vienna, Austria). A two-tailed P-value less than 0.05 was considered significant.

\section{Results}

The record reviewed that patients' number was 77 in IND/GLY, 76 in UME/VIL and 83 in TIO/OLO, respectively. A majority of patients in the current study were male (88.1\%), with an average age of 70.51 years, a mean weight and height of $73.15 \mathrm{~kg}$ and $166.13 \mathrm{~cm}$, respectively (Table 1). Patients reported smoking a mean of 36.38 packs-year, however this varied between patients $(S D=22.08)$. Furthermore, nearly half of all patients had diabetes (46.8\%), and 34 to $37 \%$ had hypertension. Coronary artery disease and chronic heart failure were present in 28 to $32 \%$ of the study population. Medication type was independent of presence or type of comorbidity.

There were no significant differences observed in FEV1 and FVC changes from baseline between patients treated with different medications. Patients treated with TIO/OLO achieved greater lung function improvement compared with those with other two dual bronchodilator agents. Patients had the highest FEV1 $(98.7 \pm 38.0 \mathrm{~mL})$ and FVC $(127.3 \pm 39.4 \mathrm{~mL})$ improvement compared with baseline status than those

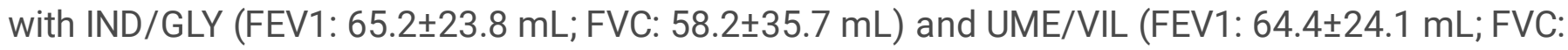
$79.1 \pm 35.2 \mathrm{~mL})(p<0.001)$. (Table 2) Significant differences in FEV1 and FVC improvements after 12 months of treatment were observed (Figure 1). Patients treated with IND/GLY and UME/VIL did not different significantly in terms of FEV1 and FVC improvement; however, TIO/OLO users did have a significantly increased lung function parameters after 12 months of treatment (Figure 2).

Additionally, quality of life with CAT score differences was significantly differences in patients treated with TIO/OLO compared with IND/GLY or UME/VIL (Figure 3). CAT score decreases were significantly in patients with TIO/OLO treatment $(-5.6 \pm 2.6)$ than patients treated with IND/GLY $(-3.8 \pm 2.5)$ and UME/VIL 
$(-3.9 \pm 2.2) .(p=0.03)$ (Table 2$)$ Therefore, the quality of life and symptoms relief were more improved in patients with TIO/OLO compared those with other two dual bronchodilator agents.

The frequency of acute exacerbation was also reduced and significant differences in patients using TIO/OLO (4.8\%) compared with those using IND/GLY (10.4\%) and UMEC/VIL (10.5\%) $(p=0.01)$. There was still the treatment benefit for decreased $A E$ frequency in patients with TIO/OLO treatment. (Table 2 )

\section{Discussion}

The current non-randomized study compared the efficacy of three LABA/LAMA fixed-dose combination therapies in patients with COPD from Far Eastern Memorial Hospital in Taiwan over a period of 12 months. CAT score, FEV1, FVC improved after treatment with UME/VIL, IND/GLY, and TIO/OLO. Results revealed that clinical outcomes after 12 months of treatment (CAT, FEV1 and FVC differences) were significantly affected by the type of COPD medication used. All lung function measurements and symptoms were significantly improved for users of TIO/OLO compared to users of IND/GLY and UME/VIL. The differences between the effects of UME/VIL and IND/GLY were not as pronounced. Besides, there was an also statistical significance for decreased exacerbation rate in patients with TIO/OLO treatment.

Previously published studies have demonstrated the efficacy and safety of fixed dual long-acting bronchodilators for COPD patients, specifically TIO/OLO. TIO/OLO is indicated for the maintenance treatment of airflow obstruction in adults with COPD. [12] This indication is supported by results from multiple randomized phase III studies of varying duration (6-52 weeks).[11, 13-14] TIO/OLO maintenance therapy improved lung function to a greater extent than the individual components or placebo and provided clinically meaningful improvements in health-related quality of life and dyspnoea in 12- and 52week studies. Tiotropium/olodaterol consistently improved 24-h lung function in 6-week studies, providing greater benefits than the monotherapies, placebo or twice-daily fixed-dose fluticasone propionate/salmeterol. Worth noting, in the subgroup analysis from Tonado [14] and DYNAGITO study [15], combination therapy with TIO+OLO was more effective than TIO in reducing exacerbations in Japanese population compared with other races. Taken together including our results, TIO+OLO combination therapy may have a superior treatment efficacy in Asian population.

Current therapeutic policies for COPD management focus on improvement of symptoms, reduction of the risk for acute exacerbations, and reduced prognosis or mortality. Based on the treatment benefits evidenced, dual LAMA/LABA combinations play an essential role in stable COPD therapy. Long-acting inhaled bronchodilators have been demonstrated for their potential to reduce COPD exacerbations in several studies. [16-20] Among of these studies have showed that the LAMA tiotropium (TIO) has greater efficacy against exacerbations than LABAs (POET-COPD [16] INVIGORATE studies [17]). In addition, the efficacy of TIO in reducing exacerbations was shown to be non-inferior to that of fixed-dose combination therapy with inhaled corticosteroids (ICS) and LABA salmeterol (INSPIRE study). [21] In the SPARK study, fixed-dose combination therapy with IND/GLY was not superior to TIO monotherapy in reducing moderate 
and severe exacerbations. [22] Moreover, there was no significant differences in symptoms, health status, or risk of exacerbation between UMEC plus VIL and TIO. [23] Therefore, TIO have the treatment superiority for symptoms relief and reduced exacerbation compared with ICS/LABA or IND/GLY and UME/VIL.

Olodaterol (OLO) is a novel once-daily LABA bronchodilator that was effective in lung function improvement. [24-26] The combination of TIO and OLO provides additional advantages in lung function and improves health-related quality of life. [27-29] The DYNAGITO study was performed to compare the safety and efficacy of TIO/OLO dual therapy versus TIO monotherapy in reducing exacerbations in COPD patients with a history of at least one exacerbation in the previous 12 months and TIO+OLO combination therapy provided a numerically greater reduction in moderate-to-severe exacerbations than TIO monotherapy. [15] Besides, anti-inflammatory effects were the central role for reducing AE and combined with TIO plus OLO had the synergistic effect for reducing neutrophils inflammation in vitro study. [30] In fact, ideal dual bronchodilator agents should have these efficacy including: the decrease in hyperinflation and mechanical stress, the modulation of mucus production and mucociliary clearance, the improvement of symptoms fluctuation and severity, and some potential direct and indirect anti- inflammatory properties. [31] Based on previous studies, therefore, only TIO plus OLO combined bronchodilator agents have the overwhelming efficacy for COPD than other two dual bronchodilator agents from bench research, clinical trials and real-world practice.

Another treatment efficacy reason is the inhaled device. Several inhaled devices available in the treatment COPD patients using dual bronchodilator agents including Breezhaler device for IND/GLY, Ellipta device for UME/VIL and Respimat device for TIO/OLO. Ciciliani and their colleagues had compared these devices using combining in vitro mouth-throat deposition measurements, cascade impactor data and computational fluid dynamics (CFD) simulations and Respimat showed the lowest amount of particles depositing in the mouth-throat model and the highest amount reaching all regions of the simulation lung model. [32] Therefore, TIO/OLO via Respimat with greater pharmacodynamic efficacy and inhaled device benefits achieved the treatment superiority for COPD compared with other two bronchodilator agents.

Several limitation were noted in this study. First, this is not a prospective randomized study to compare these treatment efficacy. Validating the current results in terms of their clinical relevance will require further well-designed randomized controlled trials. Second, there was relative small population to enroll the study. It should include large population to confirm these results. Third, the study period was only 12 months. It needed to long time to follow these treatment effectiveness. Fourth, the study performance was only one center and it may have potential bias. The study was the first time, head-to head comparison the efficacy in these different kinds LABA/LAMA fixed combination agents, though there was some limitations and bias.

\section{Conclusion}

This report is a brief summary of three fixed dual long-acting bronchodilators (UME/VIL, IND/GLY, and TIO/OLO) used on patients with COPD in a Taiwanese medical center (FEMH). Statistically significant 
improvement in pulmonary function parameters, symptoms relief and exacerbation reduction were found in all three medications after 12 months of treatment. Specifically, TIO/OLO demonstrated higher therapeutic effects compared with two other drugs. Whether this effect is clinically relevant will require further well-designed randomized studies.

\section{Abbreviations}

chronic obstruction pulmonary disease :COPD

long-acting beta agonist :LABA

long-acting muscarinic antagonist :LAMA

umeclidinium and vilanterol inhalation powder :UME/VIL , indacaterol and glycopyrronium: IND/GLY

tiotoprium and olodaterol :TIO/OLO

COPD assessment test: CAT

fixed-dose combination: FDC

forced expiratory volume in 1 second: FEV1

forced vital capacity: FVC

acute exacerbation: $\mathrm{AE}$

\section{Declarations}

The Manuscript reports studies involving human participants, human data and statement on ethics approval and consent is IBR Number: 107006-E and the name of the ethics committee is Research Ethics Review Committee, Far Eastern Memorial Hospital.

\section{Consent for publication}

Not applicable

\section{Availability of data and material}

The data will not be shared with a reason

\section{Funding}

There was no any funding in this study. 


\section{Competing interests}

The authors declare that they have no competing interests.

\section{Authors' contributions}

Dr. Cheng participated in its design and coordination and drafted the manuscript. All authors read and approved the final manuscript.

\section{Acknowledgments}

This study was supported by grants from the Far Eastern Memorial Hospital

(numbers: FEMH-2018-D-005).

\section{References}

1. Chen JC, Mannino DM. Worldwide epidemiology of chronic obstructive pulmonary disease. Curr Opin Pulm Med 1999; 5: 93-9.

2. Murray CJ, Lopez AD. Alternative projections of mortality and disability by cause 1990-2020: global burden of disease study. Lancet 1997; 349: 1498-1504.

3. Ko FW, Hui DS, Lai CK. Worldwide burden of COPD in high- and low-income countries. Part III. AsiaPacific studies. Int J Tuberc Lung Dis 2008; 12: 713-17.

4. Cheng SL et al. COPD in Taiwan: a National Epidemiology Survey. Int J Chron Obstruct Pulmon Dis 2015; 10: 2459-67.

5. Lim S et al. Impact of chronic obstructive pulmonary disease (COPD) in the Asia-Pacific region: the EPIC Asia population-based survey. Asia Pac Fam Med. 2015; 14:4.

6. Kuo LC, Yang PC, Kuo SH. Trends in the mortality of chronic obstructive pulmonary disease in Taiwan, 1981-2002. J Formos Med Assoc 2005; 104: 89-93.

7. Barrecheguren M, Monteagudo M, Ferrer J, Borrell E, Llor C, Esquinas C, Miravitlles M. Treatment patterns in COPD patients newly diagnosed in primary care. A population-based study. Respir Med 2016; 111: 47-53.

8. Wedzicha JA, Banerji D, Chapman KR, et al. Indacaterol-Glycopyrronium versus SalmeterolFluticasone for COPD. N Engl J Med. 2016 Jun 9;374(23):2222-34.

9. Vogelmeier CF, Criner GJ, Martinez FJ, et al. Global Strategy for the Diagnosis, Management, and Prevention of Chronic Obstructive Lung Disease 2017 Report. GOLD Executive Summary. Am J Respir Crit Care Med. 2017 Mar 1;195(5):557-582.

10. Siler TM, Donald AC, O'Dell D, Church A, Fahy WA. A randomized, parallel-group study to evaluate the efficacy of umeclidinium/vilanterol $62.5 / 25 \mu \mathrm{g}$ on health-related quality of life in patients with COPD. Int J Chron Obstruct Pulmon Dis. 2016 May 9;11:971-9. 
11. Calverley PMA, Anzueto AR, Carter K, et al. Tiotropium and olodaterol in the prevention of chronic obstructive pulmonary disease exacerbations (DYNAGITO): a double-blind, randomised, parallelgroup, active-controlled trial. Lancet Respir Med. 2018 May;6(5):337-344.

12. Spiolto (tiotropium and olodaterol) Summary of Product Characeristics. Ingelheim an Rhein, Germany: Boeringer Ingelheim International GmbH. 2017.

13. Dhillon S. Tiotropium/Olodaterol: a review in COPD. Drugs 2016; 76: 135-46.

14. Ichinose M, Taniguchi H, Takizawa A, Grönke L4, Loaiza L, Voß F et al. The efficacy and safety of combined tiotropium and olodaterol via the Respimat $\left({ }^{\circledR}\right)$ inhaler in patients with COPD: results from the Japanese sub-population of the Tonado(®) studies. Int J Chron Obstruct Pulmon Dis. 2016; 11:2017-27.

15. Ichinose $M$, Nishimura $M$, Akimoto $M$, et al. Tiotropium/olodaterol versus tiotropium in Japanese patients with COPD: results from the DYNAGITO study. Int J Chron Obstruct Pulmon Dis. 2018 Jul 13;13:2147-2156.

16. Vogelmeier C, Hederer B, Glaab T, et al. Tiotropium versus salmeterol for the prevention of exacerbations of COPD. N Engl J Med. 2011; 364 (12): 1093-1103.

17. Wedzicha JA, Calverley PM, Seemungal TA, et al. The prevention of chronic obstructive pulmonary disease exacerbations by salmeterol/ fluticasone propionate or tiotropium bromide. Am J Respir Crit Care Med. 2008;177(1):19-26.

18. Decramer ML, Chapman KR, Dahl R, et al. Once-daily indacaterol versus tiotropium for patients with severe chronic obstructive pulmonary disease (INVIGORATE): a randomised, blinded, parallel-group study. Lancet Respir Med. 2013;1(7):524-533.

19. Koch A, Watz H, Maleki-Yazdi MR, et al. Comprehensive assessment of the safety of olodaterol $5 \mu \mathrm{g}$ in the Respimat ${ }^{\circledR}$ device for maintenance treatment of COPD: comparison with the long-acting beta2-agonist formoterol. NPJ Prim Care Respir Med. 2017;27(1):60.

20. Joos GF, Aumann JL, Coeck C, et al. A randomised, double-blind, four-way, crossover trial comparing the 24-h FEV1 profile for once-daily versus twice-daily treatment with olodaterol, a novel long-acting beta2-agonist, in patients with chronic obstructive pulmonary disease. Respir Med. 2015;109(5):606-615.

21. Wedzicha JA, Calverley PM, Seemungal TA, et al. The prevention of chronic obstructive pulmonary disease exacerbations by salmeterol/ fluticasone propionate or tiotropium bromide. Am J Respir Crit Care Med. 2008; 177(1):19-26.

22. Wedzicha JA, Decramer M, Ficker JH, et al. Analysis of chronic obstructive pulmonary disease exacerbations with the dual bronchodilator QVA149 compared with glycopyrronium and tiotropium (SPARK): a randomised, double-blind, parallel-group study. Lancet Respir Med. 2013; 1(3):199-209.

23. Decramer M, Anzueto A, Kerwin E, et al. Efficacy and safety of umeclidinium plus vilanterol versus tiotropium, vilanterol, or umeclidinium monotherapies over 24 weeks in patients with chronic obstructive pulmonary disease: results from two multicentre, blinded, randomised controlled trials. Lancet Respir Med. 2014 Jun; 2(6):472-86. 
24. Feldman GJ, Bernstein JA, Hamilton A, Nivens MC, Korducki L, LaForce C. The 24-h FEV1 time profile of olodaterol once daily via Respimat ${ }^{\circledR}$ and formoterol twice daily via Aerolizer ${ }^{\circledR}$ in patients with GOLD 2-4 COPD: results from two 6-week crossover studies. Springerplus. 2014;3:419.

25. Ferguson GT, Feldman GJ, Hofbauer P, et al. Efficacy and safety of olodaterol once daily delivered via Respimat $\AA$ in patients with GOLD 2-4 COPD: results from two replicate 48-week studies. Int J Chron Obstruct Pulmon Dis. 2014;9:629-645.

26. Koch A, Pizzichini E, Hamilton A, et al. Lung function efficacy and symptomatic benefit of olodaterol once daily delivered via Respimat ${ }^{\circledR}$ versus placebo and formoterol twice daily in patients with GOLD 2-4 COPD: results from two replicate 48-week studies. Int J Chron Obstruct Pulmon Dis. 2014;9: 697-714.

27. Buhl R, Maltais F, Abrahams R, et al. Tiotropium and olodaterol fixed-dose combination versus monocomponents in COPD (GOLD 2-4) Eur Respir J. 2015;45(4):969-979.

28. Beeh KM, Westerman J, Kirsten AM, et al. The 24-h lung-function profile of once-daily tiotropium and olodaterol fixed-dose combination in chronic obstructive pulmonary disease. Pulm Pharmacol Ther. 2015; 32: 53-59.

29. Singh D, Ferguson GT, Bolitschek J, et al. Tiotropium + olodaterol shows clinically meaningful improvements in quality of life. Respir Med. 2015; 109(10):1312-1319.

30. Profita M, Bonanno A, Montalbano AM, et al. $\beta \bigotimes$ long-acting and anticholinergic drugs control TGFB1-mediated neutrophilic inflammation in COPD. Biochim Biophys Acta. 2012 Jul; 1822(7):1079-89.

31. Beeh KM, Burgel PR, Franssen FME, et al. How Do Dual Long-Acting Bronchodilators Prevent Exacerbations of Chronic Obstructive Pulmonary Disease? Am J Respir Crit Care Med. 2017 Jul 15;196(2):139-149.

32. Ciciliani AM, Langguth $P$, Wachtel $\mathrm{H}$. In vitro dose comparison of Respimat ${ }^{\circledR}$ inhaler with dry powder inhalers for COPD maintenance therapy. Int J Chron Obstruct Pulmon Dis. 2017 May 26;12:15651577.

\section{Tables}


Table 1. Descriptive statistics of demographics, clinical conditions and medications in COPD patients

\section{Characteristics}

\begin{tabular}{l} 
COPD Medicatio \\
\hline Ultibro \\
$(\mathrm{n}=77)$
\end{tabular}

Demographics

Sex

\begin{tabular}{lllll}
\hline \multicolumn{1}{c}{ Female } & $9(11.7)$ & $11(14.5)$ & $8(9.6)$ & 0.47 \\
\hline \multicolumn{1}{c}{ Male } & $68(88.3)$ & $65(85.5)$ & $75(90.4)$ & 0.61 \\
\hline Age & $71.4 \pm 7.37$ & $71.3 \pm 7.6$ & $69.6 \pm 7.8$ & 0.47 \\
\hline Weight & $72.3 \pm 6.75$ & $73.8 \pm 7.6$ & $73.3 \pm 6.7$ & 0.39 \\
\hline Height & $167.5 \pm 7.9$ & $168.2 \pm 5.01$ & $165.2 \pm 4.9$ & 0.18 \\
\hline Smoking (pack*year) & $36.9 \pm 16.8$ & $37.8 \pm 27.94$ & $36.6 \pm 19.3$ & 0.72 \\
\multicolumn{1}{l}{ Comorbidities } & & & & \\
\hline Diabetes & $38(49.4)$ & $35(46.1)$ & $44(53.0)$ & 0.17 \\
\hline Hypertension & $29(37.7)$ & $26(34.2)$ & $31(37.3)$ & 0.32 \\
Coronary artery disease & $25(32.5)$ & $22(28.9)$ & $24(28.9)$ & 0.75 \\
\hline Chronic heart failure & $22(28.6)$ & $23(30.3)$ & $25(30.1)$ & 0.48 \\
\hline
\end{tabular}

Note: Counts and proportion were presented for categorical variables and mean \pm SD for continuous variables

${ }^{1} \mathrm{p}$-values from Chi-Square Tests of Independence for categorical variables and ANOVA f-test for continuous variables. 
Table 2. Descriptive statistics of clinical outcomes by COPD medication

\begin{tabular}{|c|c|c|c|}
\hline \multirow{2}{*}{$\begin{array}{l}\text { Stratified by type of } \\
\text { medication }\end{array}$} & COPD I & & \multirow{2}{*}{$\begin{array}{l}p \text { - } \\
\text { value }^{1}\end{array}$} \\
\hline & $\begin{array}{l}\text { Ultibro } \\
(\mathrm{n}=77)\end{array}$ & $\begin{array}{l}\text { Anoro } \\
(\mathrm{n}=76)\end{array}$ & \\
\hline
\end{tabular}

\section{Lung function parameters}

FEV1 base (L)

$1.41 \pm 0.18$

$1.4 \pm 0.13$

$1.37 \pm 0.17$

0.64

FEV1 base (\% of predicted)

$46.74 \pm 11.9$

$45.72 \pm 8.0$

$45.59 \pm 9.3$

0.81

FEV1 12 months (L)

$1.42 \pm 0.16$

$1.45 \pm 0.14$

$1.47 \pm 0.16$

0.52

FEV1 difference after 12

$65.2 \pm 23.8$

$64.4 \pm 24.1$

$98.7 \pm 38.0$ $<.0001$

months (mL) ${ }^{2}$

FVC base (L)

FVC base (\% of predicted)

FVC 12 months (L)

FVC difference $(\mathrm{mL})^{2}$

Symptoms Scores

CAT base

CAT 12 months

CAT score difference ${ }^{2}$
$2.35 \pm 0.26$

$47.6 \pm 10.9$

$2.42 \pm 0.48$

$58.2 \pm 35.7$
$2.36 \pm 0.19$

$47.7 \pm 7.2$

$2.43 \pm 0.19$

$79.1 \pm 35.2$
$2.39 \pm 0.22$

$48.1 \pm 8.4$

$2.52 \pm 0.21$

$127.3 \pm 39.4$
0.61

0.75

0.63

$<.0001$

\section{Acute exacerbation of COPD}

\begin{tabular}{lllll} 
No & $70(90.1)$ & $68(89.5)$ & $77(92.8)$ & 0.58 \\
Yes & $8(10.4)$ & $8(10.5)$ & $4(4.8)$ & 0.01 \\
\hline
\end{tabular}

Note: Counts and proportion were presented for categorical variables and mean \pm SD for continuous variables

${ }^{1} \mathrm{p}$-values from Chi-Square Tests of Independence for categorical variables and ANOVA f-test for continuous variables.

2 FEV1, FVC, and CAT score differences were calculated by subtracting the FEV1, FVC and CAT score after 6 months of treatment to the base FEV1, FVC and CAT score

\section{Figures}


Figure 1. FEV1 differences after 12 months of treatment by COPD medications.

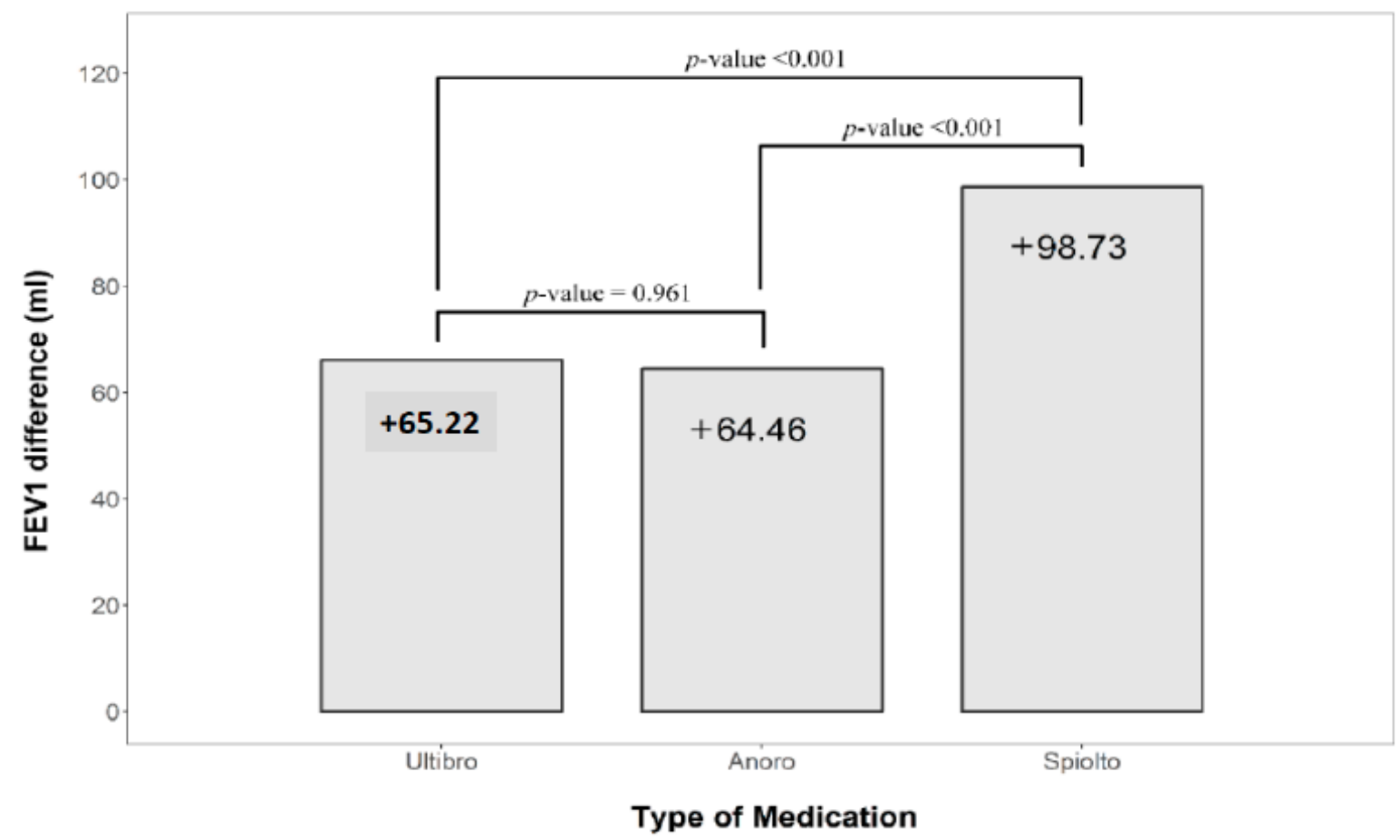

Note: Means are shown in the bar chart.

P-values were generated using Tukey's HSD (honest significant difference) for comparisons between users of different medication, $p<0.05$ was considered significant.

\section{Figure 1}

FEV1 differences after 12 months of treatment by COPD medications.

Figure 2. FVC differences after 12 months of treatment by COPD medications.

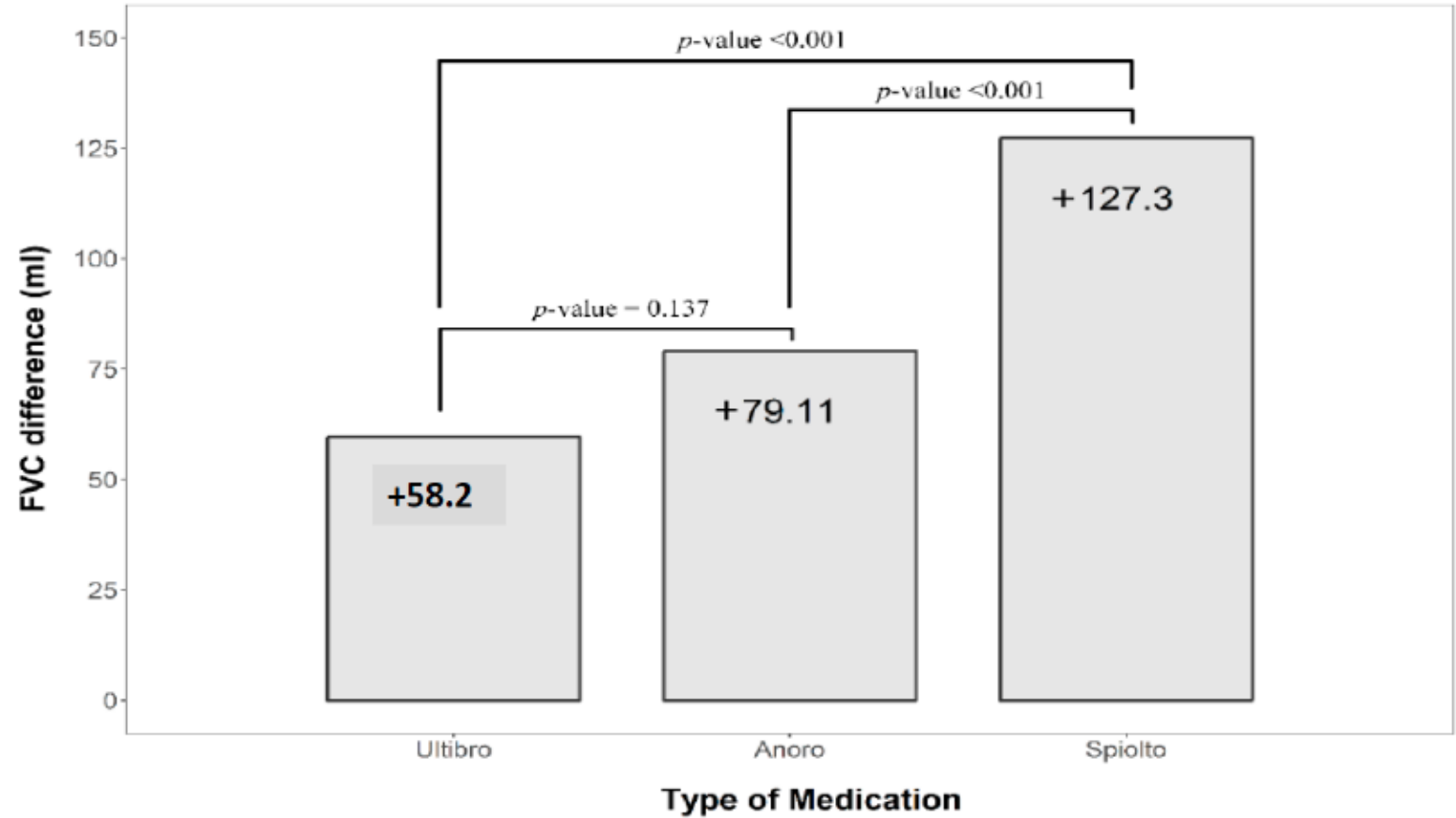

Note: Means are shown in the bar chart.

$P$-values were generated using Tukey's HSD (honest significant difference) for comparisons between users of different medication, $\mathrm{p}<0.05$ was considered significant. 
Figure 2

FVC differences after 12 months of treatment by COPD medications.

Figure 3. CAT score differences after $\mathbf{1 2}$ months of treatment by COPD medications.

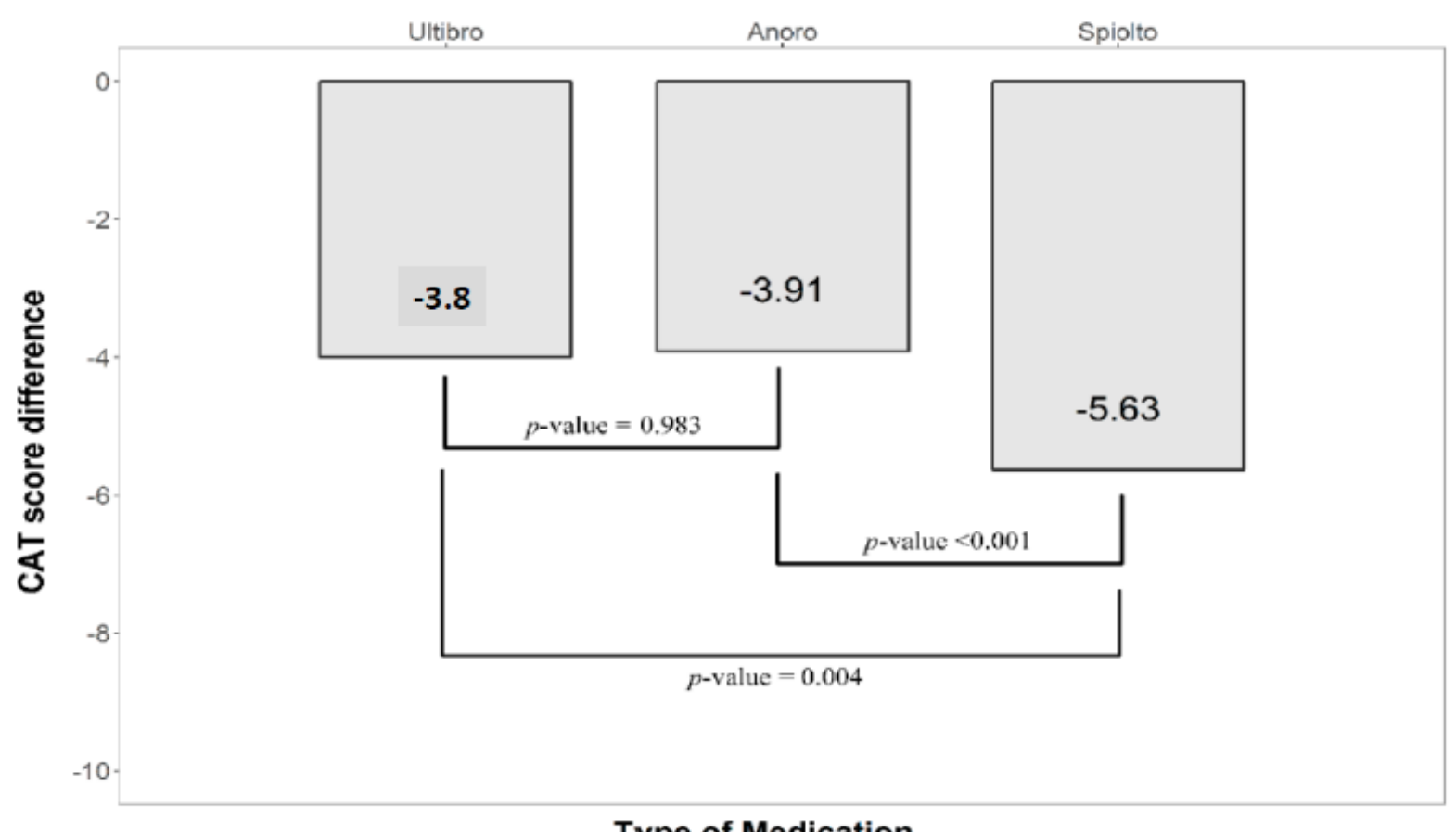

Type of Medication

Note: Means are shown in the bar chart.

P-values were generated using Tukey's HSD (honest significant difference) for comparisons between users of different medication, $\mathrm{p}<0.05$ was considered significant.

\section{Figure 3}

CAT score differences after 12 months of treatment by COPD medications. 